\title{
Correction to: Phytochromes
}

\section{Andreas Hiltbrunner}

\section{Correction to:}

Andreas Hiltbrunner (ed.), Phytochromes: Methods and Protocols, Methods in Molecular Biology, vol. 2026, https://doi.org/10.1007/978-1-4939-9612-4

In the original version of this book, Chapter 9 was inadvertently published with few errors in Table 2 data. This has now been rectified in this revised version of the book.

In Table 2 , the units $\mu \mathrm{mol} / \mathrm{m}^{2}$ s should $\mathrm{read} \mathrm{m}^{2} / \mathrm{mol}$.

In the original version of this book, Chapter 20 was inadvertently published with few errors in reference list. This has now been rectified in this revised version of the book.

The last reference in the reference list on page 261 is numbered with 5 and the first reference on page 262 is numbered with 5 . This second appearance of Reference 5 has been updated as 6 and all numbers from Reference List above 6 have been increased by 1 .

The updated online version of these chapters can be found at https://doi.org/10.1007/978-1-4939-9612-4_9

https://doi.org/10.1007/978-1-4939-9612-4_20 